EPJ Web of Conferences 33, 02007 (2012)

DOI: $10.1051 /$ epjconf/20123302007

(C) Owned by the authors, published by EDP Sciences, 2012

\title{
Electrochemical preparation of hematite nanostructured films for solar hydrogen production
}

\author{
N. Kazemi ${ }^{1, \mathrm{a}}$, A. Maghsoudipour ${ }^{2}$, and T. Ebadzadeh ${ }^{2}$ \\ ${ }^{1}$ Materials and Energy Research Center, Nanotechnology and Advanced Materials Department, \\ 31787-316 Alborz, Iran \\ ${ }^{2}$ Materials and Energy Research Center, Ceramic Department, 31787-316 Alborz, Iran
}

\begin{abstract}
Photoelectrochemical water splitting is a clean and promising technique for using a renewable source of energy, i.e., solar energy, to produce hydrogen. In this work electrochemical formation of iron oxyhydroxide and its conversion to hematite $(\alpha-$ $\mathrm{Fe}_{2} \mathrm{O}_{3}$ ) through thermal treatment have been studied. Oxyhydroxide iron compounds have been prepared onto $\mathrm{SnO}_{2} / \mathrm{F}$ covered glass substrate by potential cycling with two different potential sweep rate values; then calcined at $520{ }^{\circ} \mathrm{C}$ in air to obtain $\alpha-\mathrm{Fe}_{2} \mathrm{O}_{3}$ nanostrutured films for their implementation as photoanode in a photoelectrochemical cell. X-ray diffraction analysis allowed finding that iron oxides films have nanocrystalline character. Scanning electron microscopy revealed that films have nanostructured morphology. The obtained results are discussed considering the influence of potential sweep rate employed during the preparation of iron oxyhydroxide film on optical, structural and morphological properties of hematite nanostructured films. Results show that films have acceptable characteristics as photoanode in a photoelectrochemical cell for hydrogen generation from water.
\end{abstract}

\section{Introduction}

Photoelectrochemical (PEC) water splitting as a clean and environment friendly mean to produce hydrogen from a renewable source has recently received considerable attention. A lot work has been reported using this method since Fujishima and Honda [1] first demonstrated the photoelectrochemical behaviour of $\mathrm{TiO}_{2}$ photoelectrode in contact with aqueous solution. Hematite $\left(\alpha-\mathrm{Fe}_{2} \mathrm{O}_{3}\right)$ on account of its ideal band gap energy of 1.9 to $2.2 \mathrm{eV}$ [2-4], abundance, non-toxiticy and chemical stability in wide $\mathrm{pH}$ range remains a promising photoanode material [5-7]. Although hematite possess many advantages, but due to some limitations like short hole diffusion length, high carrier recombination rate and conduction band edge position [8], PEC performance of the hematite photoanode is much below its theoretical solar to chemical conversion efficiency of $12.9 \%$ [9].

Nanodimension morphologies provide short diffusion distance for photo-generated holes to reach electrolyte and facilitate carrier separation. Therefore, in order to prepare smaller feature size at film surface, tailoring hematite structure has been the subject of several studies. [3, 11-13].

a e-mail : na.kazemi@gmail.com

This is an Open Access article distributed under the terms of the Creative Commons Attribution License 2.0, which permits unrestricted use, distribution, and reproduction in any medium, provided the original work is properly cited. 
Various methods have been used for the synthesis of hematite nanostructured films: aqueous chemical growth [14], spray pyrolysis [15, 16], ultrasonic spray-pyrolysis [17], chemical vapour deposition (CVD) [18], sol-gel [19] and electrodeposition [20]. Electrodeposition is an emerging method. It could be well-suited to the preparation of nanostructures by proper parameter control. Moreover, it is low-cost [21], suitable for production of large scale structures and provides proper electrical contact between electrode material and substrate [22]. Present paper reports a comparative study of electrochemical growth of hematite by means of cyclic voltammetry in different electrodeposition conditions. In this study an alternative potential sweep rate has been used and morphological and structural properties of obtained nanostructures have been investigated.

\section{Experimental setups}

Electrodeposition was carried out using a standard three electrode electrochemical cell. The counter electrode was platinum, the reference electrode was saturated calomel electrode (SCE) and the working electrode was fluorine-doped tin oxide (FTO, TEC8, Dyesol). The electrodeposition bath consisted of an aqueous solution of $10 \mathrm{mM} \mathrm{FeCl}_{3}+20 \mathrm{mM} \mathrm{KF}+1 \mathrm{M} \mathrm{H}_{2} \mathrm{O}_{2}+0.1 \mathrm{M} \mathrm{KCl}$ and was heated up to $50{ }^{\circ} \mathrm{C}$. To prepare oxyhydroxide compounds of $\mathrm{Fe}(\mathrm{III})$ thin film the potential range of cyclic voltammetry procedure was 0.5 to $-0.9 \mathrm{~V} / \mathrm{SCE}$ with sweep rate of 0.02 and $0.1 \mathrm{~V} / \mathrm{s}$ for 5,10 , 20 and 40 cycle numbers. Calcination of oxyhydroxide compounds of iron(III) was done at $520{ }^{\circ} \mathrm{C}$ in air to obtain $\alpha-\mathrm{Fe}_{2} \mathrm{O}_{3}$ nanostrutured films. Characterization was performed by an X-ray diffractometer (Philips X'Pert MPD) using a $\mathrm{Cu} \mathrm{K} \alpha$ radiation and field emission scanning electron microscopy (S4160-Hitachi).

\section{Results and discussion}

The present electrodeposition route is based on reduction of hydrogen peroxide in presence of dissolved $\mathrm{Fe}$ (III) ions. Electrodeposition bath contains $\mathrm{FeCl}_{3}$ and $\mathrm{KCl}$ as supplier of iron ion and supporting electrolyte, respectively. The order of adding materials to solution is crucial. Potassium fluoride should be added before hydrogen peroxide to prevent reduction of $\mathrm{Fe}$ (III) to $\mathrm{Fe}$ (II) by formation of $\mathrm{FeF}^{2+}$ in advance.

Applied potential to electrolyte/FTO interface varied from 0.5 to $-0.9 \mathrm{~V} / \mathrm{SCE}$ in each cycle. The potential was applied from 0.5 to $0.0 \mathrm{~V}$ to minimize reduction of $\mathrm{Fe}$ (III) to $\mathrm{Fe}$ (II) during electrodeposition. According to Reaction 1, in potential range from 0.0 to $-0.7 \mathrm{~V}$ the hydrogen peroxide reduction occurs and oxyhydroxide compounds of iron(III) is produced (Reaction 2) [23]. In potential range from -0.7 to $-0.9 \mathrm{~V}$, the precursor film partially reduces. In reverse cycle both reduction and formation of oxyhydroxide compounds of iron take place, but from -0.5 to $0 \mathrm{~V}$ film formation is dominant reaction.

$$
\begin{gathered}
\mathrm{H}_{2} \mathrm{O}_{2}+2 \mathrm{e}^{-} \rightarrow 2 \mathrm{OH}^{-} \\
\mathrm{FeF}^{2+}+3 \mathrm{OH}^{-} \rightarrow \mathrm{FeOOH}+\mathrm{F}^{-}+\mathrm{H}_{2} \mathrm{O}
\end{gathered}
$$

Films were prepared at two different potential sweep rates and then calcined at $520{ }^{\circ} \mathrm{C}$ in air for 30 minutes. Dehydration reaction occurs during calcination and $\alpha-\mathrm{Fe}_{2} \mathrm{O}_{3}$ was formed. X-ray diffraction pattern of a typical hematite film prepared on FTO substrate is shown in Figure 1.

According to Reaction 2, the growth of oxyhydroide compounds of iron(III) depends on $\mathrm{OH}^{-}$ anion concentration. In each cycle of electrodeposition procedure at a defined potential range of electroformation of $\mathrm{OH}^{-}$is the main reaction, therefore, at different potential sweep rates, the local concentration of hydroxide anion in the vicinity of working electrode changes. Thickness of film is also another factor that affects hydroxide anion concentration during electrodeposition. After formation of the first layer, electron transportation from electrode to electrolyte is performed through 


\section{$2^{\text {nd }}$ European Energy Conference}

previously formed film. When film thickness increases, electron conduction and therefore growth rate decrease.

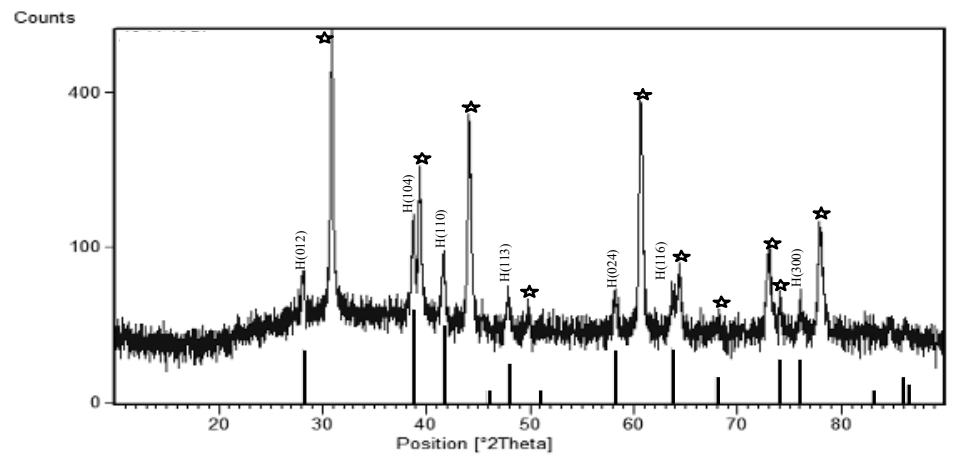

Fig. 1. XRD pattern of the iron(III) oxyhydroxide compounds after annealing at $520{ }^{\circ} \mathrm{C}$ for $30 \mathrm{~min}$. Black lines are related to hematite JCPDS pattern. $(*$, indicates the peaks originated from the FTO substrate and hematite peaks marked with $\mathrm{H}$ with their respective plane indices).

Average crystallite size of each sample was measured by the Sherrer formula. Samples of almost the same thickness but different sweep rate potential were compared. For samples prepared at potential sweep rate of 0.02 and $0.1 \mathrm{~V} / \mathrm{s}$, the average crystallite size were $60 \mathrm{~nm}$ and $69 \mathrm{~nm}$, respectively. From the obtained results, it can be concluded that when the thickness of samples is the same, the average crystallite size deposited by higher potential sweep rate is smaller. Figure 2 shows FESEM images of samples of almost same thickness. The particle size of sample 1 (Figure 2(a)) is smaller than sample 2 (Figure 2(b)), although the former has the feature size larger than the latter (Figure 2(c) and (d)).
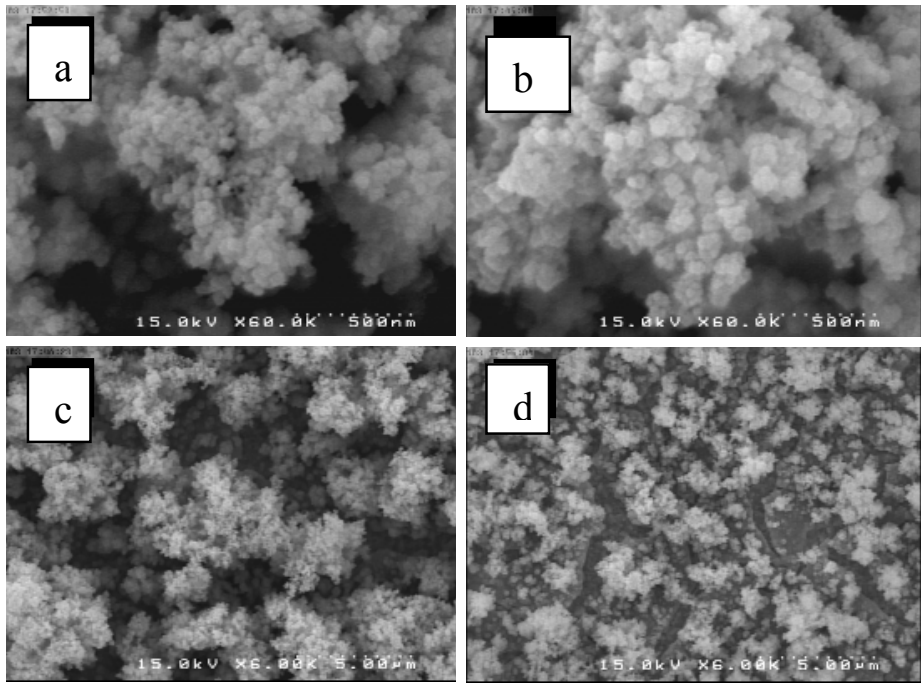

Fig. 2. FESEM images of $\alpha-\mathrm{Fe}_{2} \mathrm{O}_{3}$ films with almost same thickness, electrodeposited at potentiel sweep rate of $0.1 \mathrm{~V} / \mathrm{s}$ (a) and (c) (sample 1) and $0.02 \mathrm{~V} / \mathrm{s}$ (b) and (d) (sample 2). All magnification 600,000.

Electrodeposition was performed 5, 10, 20 and 40 cycles at each potential sweep rate. Figure 3 shows average crystallite size of samples prepared at $0.02 \mathrm{~V} / \mathrm{s}$. Descending trend of chart while the 
number of cycles increases, can be explained by decreasing of electron conduction as a result of film growth and thickness increase.

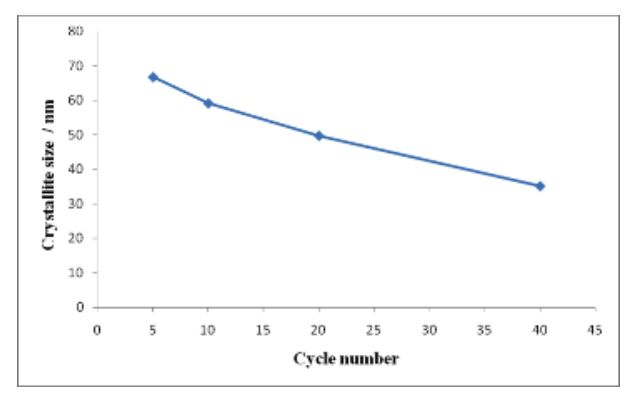

Fig. 3. Average crystallite size of samples prepared at $0.02 \mathrm{~V} / \mathrm{s}$ for $5,10,20$ and 40 cycles calculated with Scherrer formula.

FESEM pictures of hematite films prepared at $0.02 \mathrm{~V} / \mathrm{s}$ are shown in Figure 4. Grain size at the films' surface decreases when cycle number increases. It is approximately in agreement with crystallite size obtained by Scherrer formula. Cross section view of sample prepared at $0.02 \mathrm{~V} / \mathrm{s}$ for 20 cycles is shown in Figure 5. It can be observed that particles which are formed in earlier cycles have larger dimensions and when film formation continues the particles size decreases.
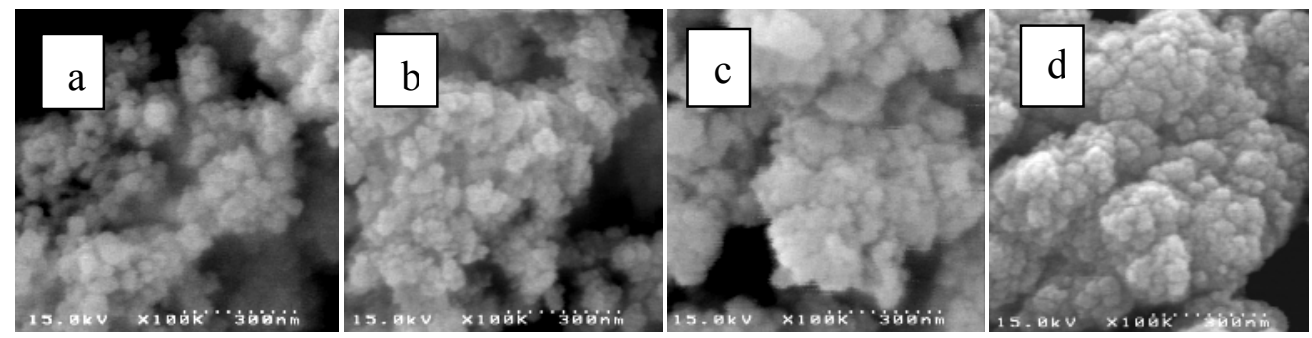

Fig. 4. FESEM images of $\alpha-\mathrm{Fe}_{2} \mathrm{O}_{3}$ films electrodeposited at potentiel sweep rate of $0.02 \mathrm{~V} / \mathrm{s}$ for (a) 5, (b) 10, (c) 20 and (d) 40 cycles.

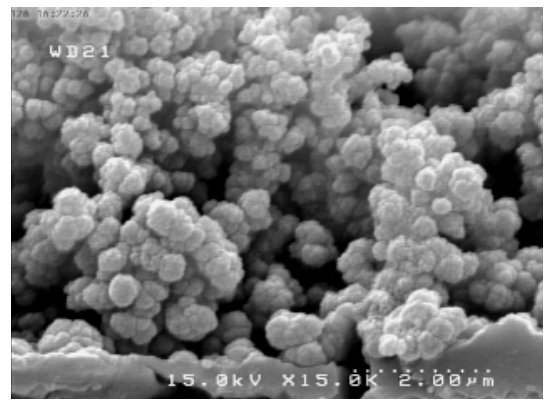

Fig. 5. Cross section view FESEM image of $\alpha-\mathrm{Fe}_{2} \mathrm{O}_{3}$ film electrodeposited at potentiel sweep rate of $0.02 \mathrm{~V} / \mathrm{s}$ for 20 cycles.

Descending trend of crystallite size, while the cycle number increases is also observed in hematite nanostructures deposited at $0.1 \mathrm{~V} / \mathrm{s}$ sweep rate, except when the sample prepared after 5 cycles (Figure 6). In this sample, although thickness is minimal, $1.01 \mu \mathrm{m}$, and electron can transport 


\section{$2^{\text {nd }}$ European Energy Conference}

easily from electrode to electrolyte, but crystallite size is smaller than samples prepared in 10 and 20 cycles. One possible explanation of this phenomenon is very high potential sweep rate at which this film is deposited. This results in too low concentration of hydroxide anions in the initial cycles of electrodeposition.

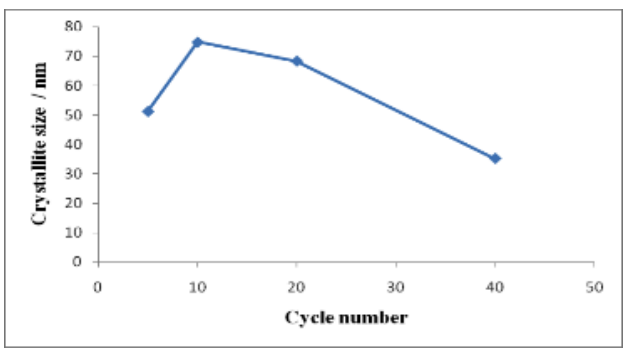

Fig. 6. Average crystallite size of samples prepared at $0.1 \mathrm{~V} / \mathrm{s}$ for $5,10,20$ and 40 cycles calculated with Scherrer formula.

Studies have been done on hematite photoanode seeking an ideal morphology, have identified many limitations. Depletion width of hematite even with adequate dopant concentration is in the range of 6 to $8 \mathrm{~nm}$ and minority carriers have short diffusion length. In other words, the carrier harvesting width in hematite is about $10 \mathrm{~nm}$. However, according to Beer-Lambert law, for sufficient absorption of incident photons, the thickness of layer should be at least $500 \mathrm{~nm}$ [24]. These restrictions show that electrode morphology can significantly change water splitting photocurrent. As a result of these characteristics, in order to photon absorption in space-charge region, the hematite films used as photoanode should not be planar.

In an optimized morphology, because of short diffusion length of minority carriers in hematite, feature size should be small enough to produce photogenerated holes close to semiconductor-liquid junction. Figure 7 shows FESEM images of hematite films electrodeposited for 20 cycles at two
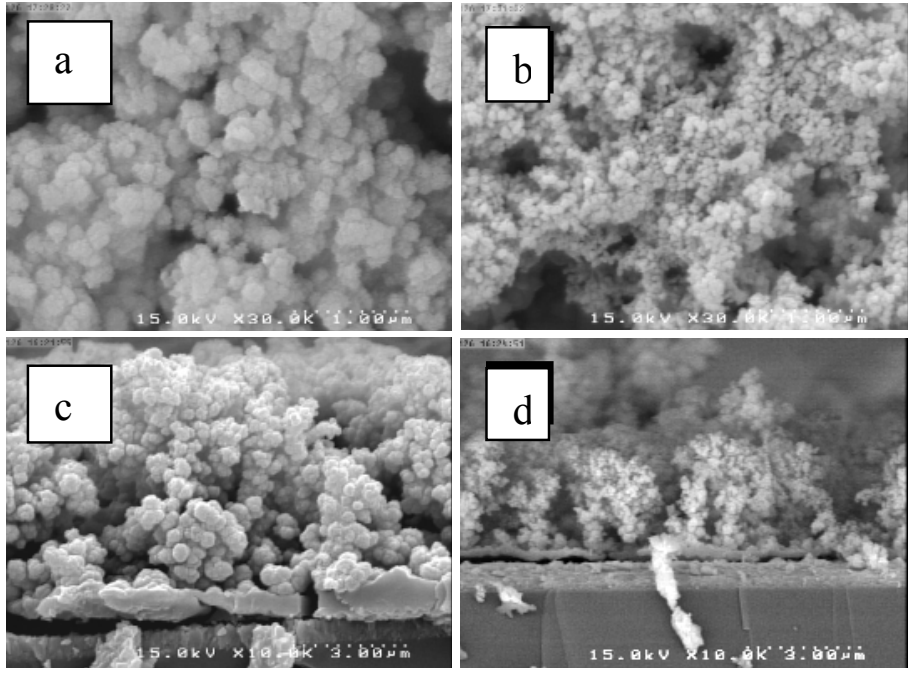

Fig. 7. FESEM images of $\alpha-\mathrm{Fe}_{2} \mathrm{O}_{3}$ films electrodeposited for 20 cycles at potentiel sweep rate of (a) $0.02 \mathrm{~V} / \mathrm{s}$ (surface view), (b) $0.1 \mathrm{~V} / \mathrm{s}$ (surface view), (c) $0.02 \mathrm{~V} / \mathrm{s}$ (cross section view) and (d) $0.02 \mathrm{~V} / \mathrm{s}$ (cross section view). 
potential sweep rates. In samples prepared using the higher sweep rate due to the smaller grain size in initial layers, the feature size is smaller. Since nucleation in each cycle takes place on first small grains which previously formed, cauliflower structure of hematite grows with thin stem. Therefore, films prepared at higher potential sweep rate have smaller feature size.

Ideal film structure should provide direct path for electron to reach conductive substrate. Film thickness and grain boundaries affect electron transportation. An interesting film from the point of view of small feature size and low thickness is shown in Figure 8. Sample prepared at potential sweep rate of $0.1 \mathrm{~V} / \mathrm{s}$ has small feature size and its thickness is lowest among other samples.

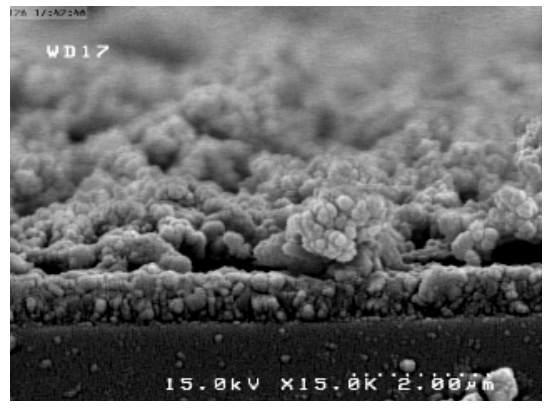

Fig. 8. FESEM images of $\alpha-\mathrm{Fe}_{2} \mathrm{O}_{3}$ films electrodeposited at potentiel sweep rate of $0.1 \mathrm{~V} / \mathrm{s}$ for 5 cycles (cross section view).

\section{Conclusions}

In this paper, the electrochemical deposition of hematite nanostructures on FTO substrate in different electrodeposition conditions was studied. It is shown how sweep rate and cycle numbers allow morphology control of films by altering hydroxide anion concentration. High potential sweep rate was used and resulted in formation of films with small feature size and low thickness expecting to provide sufficient photon absorption in space-charge region and direct path for majority carrier transportation.

\section{References}

1. A. Fujishima, K. Honda, Nature 238, 37 (1972)

2. A.A. Akl, Appl. Surf. Sci. 233, 307 (2004)

3. N. Beermann, L. Vayssieres,S.-E. Lindquist, A.Hagfeldt, J. Electrochem. Soc. 147, 2456 (2000)

4. L. Vayssieres, C. Sathe, S.M. Butorin, D.K. Shuh, J. Nordgren, J. Guo, Adv. Mater. (Weinheim, Ger.) 17, 2320 (2005)

5. P. Mishra, P. Shukla, O. Shrivastava, Int J Hydrogen Energy 32, 1680 (2007)

6. L. Mingtao, Z. Liang, G. Leijin, Int. J. Hydrogen Energy 35, 7127 (2010)

7. Y. Sun, C. Murphy, K. Reyes-Gil, E. Reyes-Garcia, J. Thornton, N. Morris, et al., Int. J. Hydrogen Energy 34, 8476 (2009)

8. M.Grätzel, Nature 414, 338 (2001)

9. A. Murphy, P. Barnes, L. Randeniya, I. Plumb, I. Grey, M. Horne, et al., Int. J. Hydrogen Energy 31, 1999 (2006)

10. T. Lindgren, H.L. Wang, N. Beermann, L. Vayssieres, A. Hagfeldt, S.E. Lindquist, Sol.Energy Mater. Sol. Cells 71, 231 (2002)

11. A. Kay, I. Cesar, M. Grätzel, J. Am. Chem. Soc. 128, 15714 (2006)

12. I. Cesar, K. Sivula, A. Kay, R. Zboril, M. Grätzel, J. Phys. Chem. C 113, 772 (2009)

13. F. Le Formal, M. Grätzel, K. Sivula, Adv. Funct. Mater. 20, 1099 (2010) 


\section{$2^{\text {nd }}$ European Energy Conference}

14. Z. Dai, Z. Pan, Z. Wang, Adv. Funct. Mater. 13, 9 (2003)

15. S. U. M. Khan and J. Akikusa, J. Phys. Chem. B 103, 7184 (1999)

16. J. D. Desai, H. M. Pathan, S. Min, K. Jung, O. Joo, Appl. Surf. Sci. 252, 1870 (2005)

17. A. Duret, M. Grätzel, J. Phys. Chem. B 109, 17184 (2005)

18. T. Maruyama, T. Kanagawa, J. Electrochem. Soc. 143, 1675 (1996)

19. H. Miyake, H. Kozuka, J. Phys. Chem. B 109, 17951 (2005)

20. R. Schrebler, K. Bello, F. Vera, P. Cury, E.Muñoz, R. del Río, H. Gómez, R. Córdova, E.A. Dalchiele, Electrochem. Solid-State Lett. 9 C110 (2006)

21. D. Lincot, Thin Solid Films 487, 40 (2005)

22. Choi, K.S. Lichetengger, H.C. Stucky, E.W. McFarland, J. Am. Chem. Soc. 124, 12402 (2002)

23. R. Schrebler, K. Bello, F. Vera, P. Cury, E.Muñoz, R. del Río, H. Gómez, R. Córdova, E.A. Dalchiele, Electrochem. Solid-State Lett. 10, D95 (2007)

24. R. Gardner, D. Tanner, F. Sweett, J. Phys. Chem. Solids 24, 1183 (1963) 